\title{
One-step Coassembled Nanocoatings on Paper for Potential Packaging Applications
}

\author{
Sonia E. Chavez, ${ }^{1,2}$ Hao Ding, ${ }^{1,2}$ Brandon L. Williams, ${ }^{1,2}$ Sunghyun Nam, ${ }^{3}$ Zaili Hou,,${ }^{1,2}$ Dongqiao Zhang, ${ }^{1,2}$ and Luyi Sun ${ }^{1,2,4, *}$
}

\begin{abstract}
Plastics films have been widely used in food packaging. But due to the environmental concerns of plastics films, there is a trend of replacing plastics films with paper for food packaging. To meet the requirements of packaging, the paper must be modified to improve its barrier properties. In this report, a sonication and dip coating method was developed to deposit a polyvinyl alcohol (PVA)/montmorillonite (MMT) nanocoating on two representative paper substrates: regular paper and cotton paper. The coated paper substrates were characterized by X-ray diffraction (XRD), scanning electron microscopy (SEM), water vapor transmission rate (WVTR), and microscale combustion calorimetry (MCC). The XRD results support the formation of well-aligned MMT nanosheets on paper substrates, and the SEM images show that most pores on the substrates were covered by the nanocoatings, which leads to a drastic decrease in WVTR of the coated substrates. The nanocoatings also led to a minor improvement in flame retardancy. The results suggest that applying nanocoating is a promising approach to improving the barrier properties of paper for potential packaging applications.
\end{abstract}

Keywords: Polyvinyl Alcohol; Montmorillonite; Paper; Nanocoating; Barrier Properties.

Received: 7 June 2021; Accepted: 13 August 2021.

Article type: Research article.

\section{Introduction}

Paper is a versatile and flexible material that can be used for printing, household products, and food packaging. ${ }^{[1,2]}$ The versatility of paper is contributed by its properties, including its low density, good mechanical properties, excellent recyclability, and biodegradability. ${ }_{.}^{[3-5]}$ But a major disadvantage of paper is its fibrous porous structure and thus poor barrier properties. ${ }^{[6,7]}$ As a result, plastic films with much higher barrier properties have replaced paper in many packaging applications and have become an essential part of everyday life. ${ }^{[8,9]}$ However, the poor degradability of plastic films has generated significant environmental concerns, supporting a renewed interest in using paper products for packaging applications. ${ }^{[10,11]}$

\footnotetext{
${ }^{I}$ Polymer Program, Institute of Materials Science, University of Connecticut, Storrs, Connecticut 06269, United States.

${ }^{2}$ Department of Chemical and Biomolecular Engineering, University of Connecticut, Storrs, Connecticut 06269, United States.

${ }^{3}$ United States Department of Agriculture, Agricultural Research

Service, Southern Regional Research Center, New Orleans, LA 70124, USA.

${ }^{4}$ Department of Biomedical Engineering, University of Connecticut,

Storrs, Connecticut 06269, United States.

*Email:luyi.sun@uconn.edu (L. Sun)
}

To increase the use of paper-based packaging, modification of paper is essential to improve the key properties to meet specific application requirements. For example, for food packaging applications, the most critical demand is to improve the barrier properties of paper because paper typically has a high porosity and thus a very poor barrier against gas (such as oxygen, water vapor, etc.). ${ }^{[2,13]}$ A common method to improve the barrier properties of paper is to coat a thin layer of wax on the paper surface, but this makes it more difficult to recycle the final products. ${ }^{[13-16]}$

It has been previously studied that nanocoating technology can help significantly improve the barrier properties, flame retardancy, and mechanical performance of the coated substrates. ${ }^{[17]}$ Also, the thickness of the nanocoatings is significantly lower than the conventional coatings (including the wax coating on paper), and thus a minimal concern on cost. Herein, we aim to improve the barrier properties and flame retardancy of paper substrates for food packaging applications Both commercial recycled regular paper and cotton paper are selected as two representative substrates. A previously developed coating method of combining a polyvinyl alcohol (PVA) binder and montmorillonite (MMT) nanosheets was adopted to form the coating suspension. ${ }^{[17]}$ PVA was chosen because of its high film-forming capability, ${ }^{[18]}$ excellent adhesion with hydrophilic substrates, ${ }^{[17]}$ high degradability, ${ }^{[19]}$ 
and safety for food contact. ${ }^{[20]}$ MMT nanosheets have demonstrated, when used in nanocomposites, excellent multifunctionality such as improving barrier, ${ }^{[2]]}$ mechanical, ${ }^{[22]}$ thermal, ${ }^{[23,24]}$ and flame retardant properties. ${ }^{[25-28]}$ Besides, MMT, a natural clay, is less expensive compared to many other 2D nanosheets that may exhibit similar performance improvements, ${ }^{[29,30]}$ and thus is chosen for this investigation.

\section{Experimental}

Commercially available multi-purpose regular paper (Boise Aspen 30 premium recycled paper, $75 \mathrm{~g} / \mathrm{m}^{2}$ ) and $100 \%$ cotton paper (Southworth, $90 \mathrm{~g} / \mathrm{m}^{2}$ ) were selected as substrates. PVA [EXCEVAL ${ }^{\mathrm{TM}}$ AQ-4104; 98.0 mol. \% of hydrolysis], MMT (PGN nanoclay; Minerals Technologies Inc., New York, USA), glutaraldehyde (GA) (50\% aqueous solution; Sigma-Aldrich), and $\mathrm{HCl}$ (37\%; Sigma-Aldrich) were used as received without further purification.

PVA was dissolved in deionized (DI) water at $90^{\circ} \mathrm{C}$ with the assistance of stirring. MMT was dispersed in DI water under stirring, followed by 1 hour of sonication in a sonication bath (Branson 8510R-MT, $250 \mathrm{~W}, 44 \mathrm{kHz}$ ). A 1.5 wt.\% PVA/MMT (0.75 wt.\% PVA and 0.75 wt.\% MMT, 98.50 wt. \% $\mathrm{H}_{2} \mathrm{O}$ ) aqueous dispersion was obtained from predetermined amounts of the prepared PVA solution and MMT dispersion. To ensure uniformity of the PVA/MMT dispersion, it was stirred for an hour and followed by 1 hour of sonication. The dispersion was then cooled in an ice bath, and a small amount of crosslinking agent GA was added at a mole ratio of 1:20 (GA: PVA-OH groups). $\mathrm{HCl}$ was also added as the crosslinking reaction catalyst (1:5 mole ratio to GA).

To prepare the paper substrates (ca. $15 \mathrm{~cm} \times 17 \mathrm{~cm}$ ), they were dehydrated in an oven at $60{ }^{\circ} \mathrm{C}$ for $24 \mathrm{~h}$. Each sample was then submerged in the PVA/MMT dispersion for five minutes of sonication (Branson 8510R-MT, $250 \mathrm{~W}, 44 \mathrm{kHz}$ ) and then dried vertically for 45 minutes at $60{ }^{\circ} \mathrm{C}$. The paper substrates were dip coated four times while rotating them $180^{\circ}$ between coating cycles to ensure a complete substrate coverage and smooth out the thickness gradient. The experimental procedures for fabricating the nanocoating on paper are depicted in Fig. 1. The weight uptakes after coating for regular paper and cotton paper were 6.2 and $3.8 \mathrm{wt} . \%$, respectively. The difference in the weight uptake between the two types of paper was attributed to surface enhancements and finishes, which are usually carried out to improve the texture and printability.

The X-ray diffraction (XRD) patterns of the coated paper substrates were recorded using a Bruker D2 phaser with a LynxEye liner detector. The mechanical properties of the coated substrates were tested on a dynamic mechanical analyzer (DMA, TA Instruments Q800). An FEI nova NanoSEM 450 scanning electron microscope (SEM) was used to capture surface images of the samples. The samples were sputter-coated with a thin layer (ca. $6 \mathrm{~nm}$ ) of $\mathrm{Au} / \mathrm{Pd}(80: 20)$ before SEM imaging.

To better assess the water vapor transmission rates (WVTRs) of the paper samples, two different methods were adopted: (1) the specimens were tested on a MOCON PERMATRAN-W $1 / 50 \mathrm{WVTR}$ tester at $23{ }^{\circ} \mathrm{C}$ and $50 \% \mathrm{RH}$ following ASTM E398 (hereafter referred to as MOCON method). (2) A simple bench-top method adapted from ASTM E96/E96M was also developed, which was widely used in industry. The testing procedures are illustrated in Fig. 2. First, a 1:1 ratio mixture of beeswax and rosin is heated to $150{ }^{\circ} \mathrm{C}$. The jars $(20.3 \mathrm{~cm}$ in diameter and $10.2 \mathrm{~cm}$ in height, with amouth diameter of $7.2 \mathrm{~cm}$ ) are filled with DI with ca. $1 / 4$ inch of headspace. The testing specimens are cut into appropriate dimensions to fit the top of the jars. The Beeswax/rosin mixture is thoroughly combined and applied to the rim of the jars. The testing specimen is placed on the rim of the jars and sealed. They are then placed in a chamber, where saturated

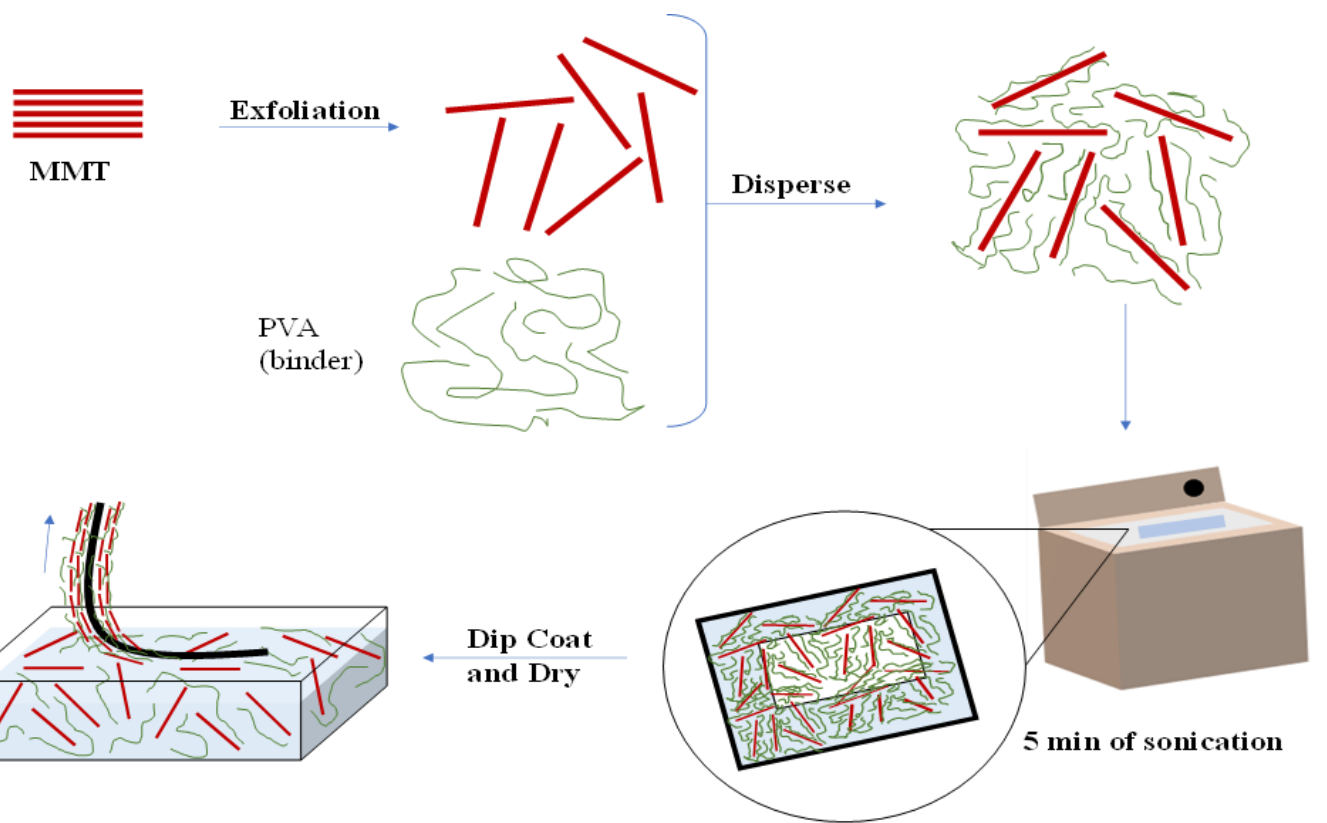

Fig. 1 Schematic of the procedures to prepare PVA/MMT nanocoatings on paper substrates. 


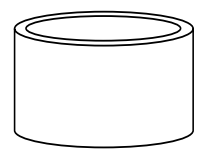

Headspace: $1 / 4$ inch
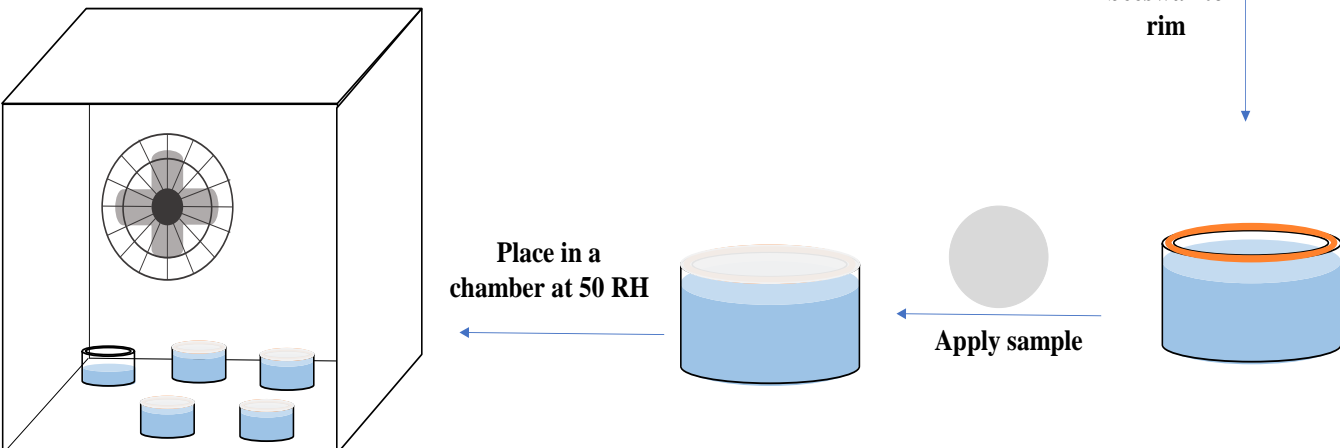

Fig. 2 Schematic of the benchtop method to test the WVTR of the coated regular paper and cotton paper.

sodium chloride solution is used to maintain a $50 \%$ relative humidity (RH). During 50 hours, the jars are weighed every 2 hours. From the collected data the slope of the straight line of the change in mass versus time, i.e., the weight loss rate was determined. The WVTR is then calculated according to Equation 1.

$$
\mathrm{WVTR}=\frac{\text { slope }(\mathrm{g} / \mathrm{h})}{\text { Test area }\left(\mathrm{m}^{2}\right)}
$$

The horizontal burning test was conducted on a wire grid. All the samples were $12.5 \mathrm{~cm}$ in length and $1.5 \mathrm{~cm}$ in width, and the flame height is $4 \mathrm{~cm}$. The flame was placed $2.2 \mathrm{~cm}$ from the sample. The total heat release (THR) and heat release rate (HRR) of the samples were tested on a microscale combustion calorimeter (MCC, Govmark, model MCC-3) at a $1{ }^{\circ} \mathrm{C} / \mathrm{s}$ heating rate using method A of ASTM D7309.

\section{Results and Discussion}

A dip coating method was used because it is well-established, scalable, and most readily to be adopted in the papermaking industry. A brief sonication treatment was introduced during dip coating to help better impregnate the coating ingredients, i.e., PVA polymer chains and MMT nanosheets, into the pores of the paper substrates to achieve the best possible surface coverage, but meanwhile, minimize potential damage to the paper structure. ${ }^{[31]}$ The coated samples were then hung vertically in an oven to generate liquid flow on the paper surface, which helped induce the alignment of the MMT nanosheets. ${ }^{[17]}$ During the process, MMT nanosheets and PVA chains are allowed to self-coassemble into a nanocoating on the paper surface. In this coating, MMT nanosheets were wellaligned along the substrate, leading to significantly improved barrier properties. ${ }^{[32]}$ The dispersion of $1.5 \mathrm{wt} . \%$ of solids (PVA + MMT) was chosen to maintain a low viscosity for a quick flow to facilitate orientation.

The orientation of MMT nanosheets is the most important factor in determining the quality of the nanocoating. An initial evaluation of the MMT orientation on various substrates was conducted by collecting their XRD patterns. As shown in Fig.
3 , the diffraction peak of the pristine MMT was detected at a $2 \theta$ value of $7.32^{\circ}$ with a $d$-spacing of $12.1 \AA$. The uncoated regular paper and cotton paper shows no peaks in the lowangle region. Once coated, the basal diffraction peaks signified MMT nanosheet orientation within the nanocoatings. The increase in the interlayer distance of the MMT layers within the nanocoatings on regular paper $(25.2 \AA)$ and cotton paper $(25.7 \AA)$ supports the presence of the PVA binder within the MMT nanosheet layers.

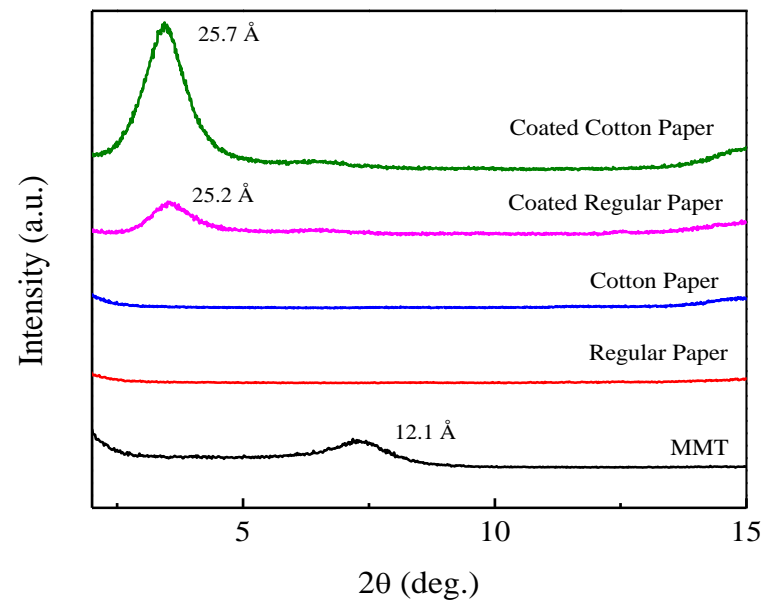

Fig. 3 XRD patterns of the regular paper and cotton paper before and after a PVA/MMT nanocoating.

Due to its porous structure, paper exhibits poor barrier properties. The key goals of the sonication and coating treatment are to fill the internal pores and to cover surface defects, respectively. SEM imaging was used to observe the surface morphology after coating treatment. As shown in Fig. 4 , the uncoated regular paper and cotton paper both contain large pores throughout the structure. By sonication and coating treatment, most pores on paper were filled (Fig. 4). But it can be observed that the coated regular paper and cotton paper still contain some small pores. One of the reasons for the incomplete coverage is probably the limited sonication 
treatment. Unfortunately, a longer sonication treatment or repetition of sonication cycles may damage the overall structure of the paper and thus is not desirable. ${ }^{[11,31]}$ Also, it was

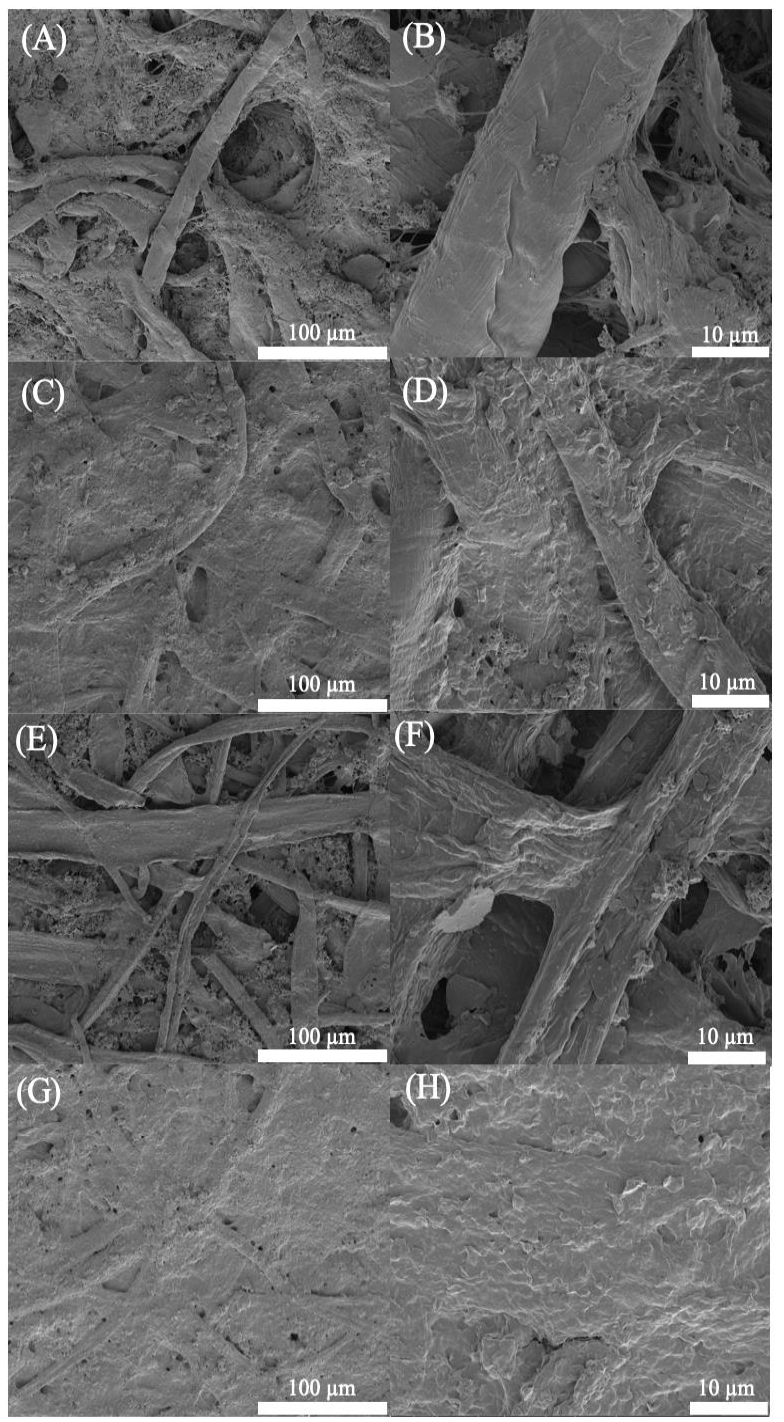

Fig. 4 SEM images of the cotton paper (A) and (B), the coated cotton paper (C) and (D), the regular paper (E) and (F), and the coated regular paper $(\mathrm{G})$ and $(\mathrm{H})$.

observed during the experiment that the paper substrates started to deteriorate after more than 5 minutes of sonication. To further determine the overall quality of the nanocoatings, the WVTRs of the coated paper samples were tested. Since XRD and SEM characterize a very small area of the coated substrates, their results represent structural properties at localized regions. On the other hand, WVTR tests examine a much larger area of the sample. Two different methods were used to determine the WVTRs and the results are summarized in Table 1. Both regular paper and cotton paper possess a significantly improved battier against water vapor after coating treatment. According to the MOCON method, the WVTRs of the regular paper and cotton paper dropped from 2511.1 to $240.9 \mathrm{~g} \cdot$ day $^{-1} \cdot \mathrm{m}^{-2}$ and from 1718.3 to $283.5 \mathrm{~g} \cdot$ day $^{-}$ ${ }^{1} \cdot \mathrm{m}^{-2}$, respectively. Similar trends were also observed from the bench-top testing data. These results indicate that the nanocoating has covered the majority of the paper substrate to reduce the WVTR, which is very beneficial for certain applications like food packaging.

Table 1. WVTRs of the coated regular paper and cotton paper.

\begin{tabular}{lcc} 
Sample & $\begin{array}{c}\text { WVTRMocon } \\
\left(\mathrm{g} \cdot \text { day }^{-1} \cdot \mathrm{m}^{-2}\right)\end{array}$ & $\begin{array}{c}\text { WVTRBench-top } \\
\left(\mathrm{g} \cdot \text { day }^{-1} \cdot \mathrm{m}^{-2}\right)\end{array}$ \\
\hline Regular paper & 2511.1 & 2323 \\
Cotton paper & 1718.3 & 2239 \\
Coated regular paper & 240.9 & 252 \\
Coated cotton paper & 283.5 & 268 \\
\hline
\end{tabular}

The flammability of the coated regular paper and cotton paper was also examined and the results are shown in Fig. 5 The nanocoating did not slow down the rate of the spread of fire. However, it did promote char formation and help maintain the paper structure. After the flammability test, the uncoated samples were almost completely gasified, only leaving behind a tiny amount of ash, but the coated samples did not fall apart and maintained the overall shape.

The uncoated and coated paper substrates were also characterized by MCC to evaluate their THRs and HRRs. As shown in Fig. 6 and Table 2, the coated regular paper and cotton paper exhibited $15.6 \%$ and $21.5 \%$ reductions in THR, respectively, after coating. The uncoated regular paper and cotton paper showed the peaks of HRR (pkHRR) at ca. 358.1 and $392.8^{\circ} \mathrm{C}$, respectively. Their HRR values were 148.5 and $185.0 \mathrm{~W} / \mathrm{g}$, respectively. The coated regular paper and cotton paper exhibited noticeable reductions in pkHRR, with ca. $13.5 \%$ and $18.8 \%$, respectively as compared with those for the uncoated ones. The MCC characterization results indicate that the PVA/MMT nanocoating has a significant impact on the combustion behavior of the coated substrates and can impart flame retardancy to the substrates. This improved flame resistance was attributed to the promotion of char formation ${ }^{[33]}$ by a PVA/MMT nanocoating.

Table 2. MCC results of the uncoated and coated paper substrates.

\begin{tabular}{lllll}
\hline & pkHRR & $\begin{array}{l}\text { pkHRR } \\
\text { temperature } \\
\left({ }^{\circ} \mathrm{C}\right)\end{array}$ & $\begin{array}{l}\text { THR } \\
(\mathrm{kJ} / \mathrm{g})\end{array}$ & $\begin{array}{l}\text { THR reduction (compared to the } \\
\text { control sample) } \\
(\%)\end{array}$ \\
\hline Regular paper & $(\mathrm{W} / \mathrm{g})$ & 358.1 & 9.6 & - \\
Cotton paper & 148.5 & 392.8 & 10.2 & - \\
Coated regular paper & 185.0 & 374.3 & 8.1 & $15.6 \%$ \\
Coated cotton paper & 128.5 & 394.2 & 8.0 & $21.5 \%$ \\
\hline
\end{tabular}



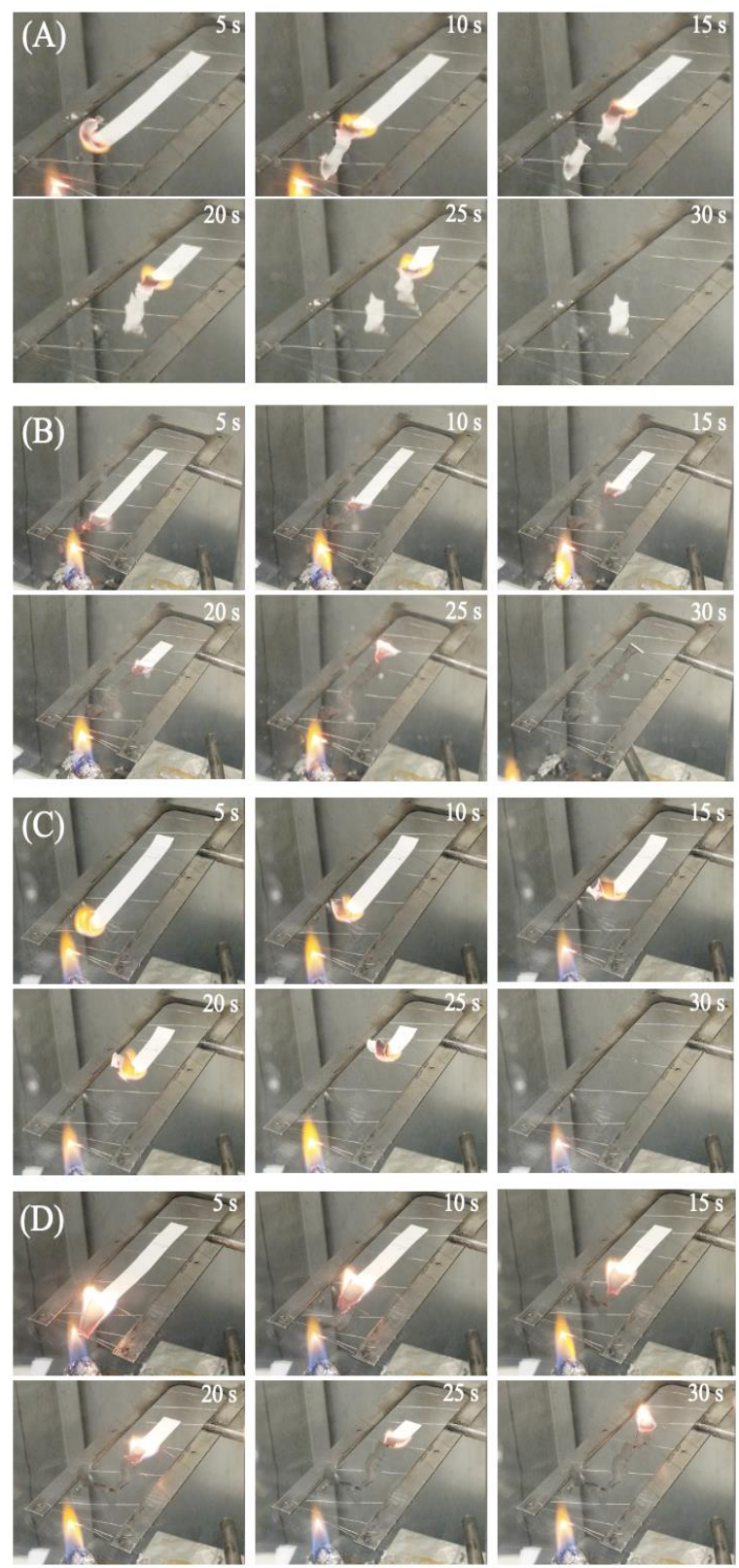

Fig. 5 Images of the combustion process of the samples: (A) regular paper, (B) coated regular paper, (C) cotton paper, and (D) coated cotton paper.

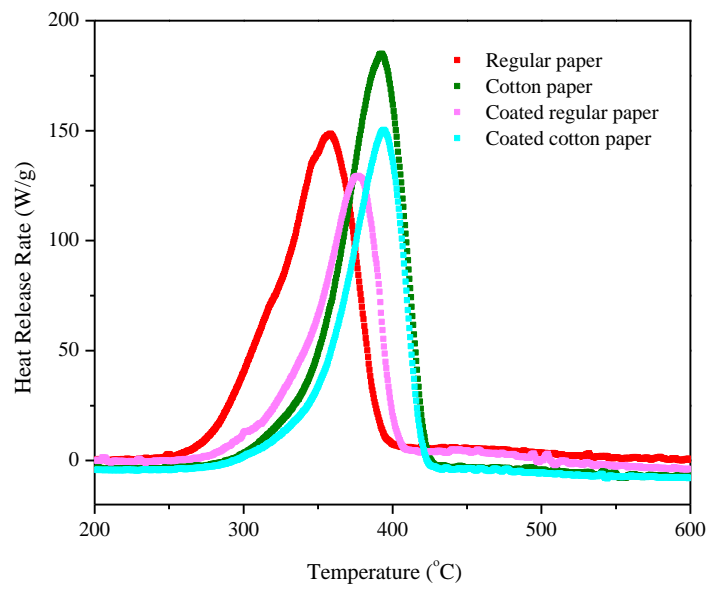

Fig. 6 Heat release rate as a function of temperature for the uncoated and coated paper substrates.

\section{Conclusion}

A sonication and dip coating method was used to deposit a PVA/MMT nanocoating on regular paper and cotton paper substrates. The characterization results of the nanocoating support that well-oriented MMT nanosheets were coated on paper substrates together with PVA, covering most pores on the substrates. As a result, the water vapor barrier property of the paper substrates was dramatically improved. The nanocoatings also led to a minor improvement in flame retardancy. The results suggest that applying nanocoating is a promising approach to improve the barrier properties of paper for potential packaging applications.

\section{Acknowledgment}

We thank the support of the National Science Foundation (CMMI-1562907).

\section{Conflict of Interest}

There is no conflict of interest.

\section{Supporting Information}

Not applicable.

\section{References}

[1] Z. Hu, C. Tang, Z. He, J. Lin, Y. Ni, BioResources, 2017, 12, 2234-2248, doi: 10.15376/biores.12.1.2234-2248.

[2] A. Barhoum, H. Rahier, R. E. Abou-Zaied, M. Rehan, T. Dufour, G. Hill, A. Dufresne, ACS Applied Materials \& Interfaces, 2014, 6, 2734-2744, doi: 10.1021/am405278j. [3] V. Rastogi, P. Samyn, Coatings, 2015, 5, 887-930, doi: 10.3390/coatings5040887.

[4] K. Khwaldia, E. Arab Tehrany, S. Desobry, Comprehensive Reviews in Food Science and Food Safety, 2010, 9, 82-91, doi: 10.1111/j.1541-4337.2009.00095.x.

[5] A. Emblem, H. Emblem, Packaging Technology: Fundamentals, materials and processes, Elsevier, Woodhead Publishing Limited, 2012.

[6] S. K. Mahadeva, K. Walus, B. Stoeber, ACS Applied Materials \& Interfaces, 2015, 7, 8345-8362, doi: 10.1021/acsami.5b00373.

[7] S. Natarajan, M. Govindarajan, B. Kumar, Fundamentals of packaging technology, PHI Learning Pvt. Ltd., 2014.

[8] S. Mangaraj, T. K. Goswami, P. V. Mahajan, Food Engineering Reviews, 2009, 1, 133-158, doi: 10.1007/s12393009-9007-3.

[9] R. R. Tummala, Fundamentals of microsystems packaging, McGraw-Hill Education, 2001.

[10] E. Amini, M. Azadfallah, M. Layeghi, R. Talaei-Hassanloui, Cellulose, 2016, 23, 557-570, doi: 10.1007/s10570-015-0846-1.

[11] K. Ghule, A. V. Ghule, B.-J. Chen, Y.-C. Ling, Green Chemistry, 2006, 8, 1034, doi: 10.1039/b605623g.

[12] D. Zhang, H. Xiao, ACS Applied Materials \& Interfaces, 2013, 5, 3464-3468, doi: 10.1021/am400585m.

[13] R. Anthony, Z. Xiang, T. Runge, Progress in Organic Coatings, 2015, 89, 240-245, doi: 10.1016/j.porgcoat.2015.09.013. 
[14] Y. Zou, J. S. Hsieh, E. Mehnert, J. Kokoszka, Progress in Organic Coatings, 2007, 60, 127-131, doi: 10.1016/j.porgcoat.2007.07.012.

[15] G. D. Moggridge, N. K. Lape, C. Yang, E. L. Cussler, Progress in Organic Coatings, 2003, 46, 231-240, doi: 10.1016/s0300-9440(02)00180-7.

[16] T. Schuman, B. Adolfsson, M. Wikström, M. Rigdahl, Progress in Organic Coatings, 2005, 54, 188-197, doi: 10.1016/j.porgcoat.2005.06.010.

[17] F. Ding, J. Liu, S. Zeng, Y. Xia, K. M. Wells, M.-P. Nieh, L. Sun, Science Advances, 2017, 3, e1701212, doi: 10.1126/sciadv. 1701212.

[18] J. Liu, S. E. Chavez, H. Ding, M. M. Farooqui, Z. Hou, S. Lin, T. D. D'Auria, J. M. Kennedy, A. M. LaChance, L. Sun, Nano Materials Science, 2022, 4, 97-103, doi: 10.1016/j.nanoms.2021.07.001.

[19] X. Tang, S. Alavi, Carbohydrate Polymers, 2011, 85, 7-16, doi: 10.1016/j.carbpol.2011.01.030.

[20] C. C. DeMerlis, D. R. Schoneker, Food and Chemical Toxicology, 2003, 41, 319-326, doi: 10.1016/s02786915(02)00258-2.

[21] W. Huang, S. Zeng, J. Liu, L. Sun, RSC Advances, 2015, 5, 58191-58198, doi: 10.1039/c5ra09598k.

[22] L. Sun, W. J. Boo, J. Liu, C. W. Tien, H. J. Sue, M. J. Marks, H. Pham, Polymer Engineering \& Science, 2007, 47, 1708-1714, doi: 10.1002/pen.20864.

[23] P. Fan, H. Liu, V. Marosz, N. T. Samuels, S. L. Suib, L. Sun, L. Liao, Advanced Functional Materials, 2021, 31, 2101380, doi: 10.1002/adfm.202101380.

[24] B. Zhang, J. Liu, M. Ren, C. Wu, T. J. Moran, S. Zeng, S. E. Chavez, Z. Hou, Z. Li, A. M. LaChance, T. R. Jow, B. D. Huey, Y. Cao, L. Sun, Advanced Materials, 2021, 33, 2170264, doi: 10.1002/adma.202170264.

[25] D. Zhang, B. L. Williams, S. B. Shrestha, Z. Nasir, E. M. Becher, B. J. Lofink, V. H. Santos, H. Patel, X. Peng, L. Sun, Journal of Colloid and Interface Science, 2017, 505, 892-899, doi: 10.1016/j.jcis.2017.06.087.

[26] D. Zhang, B. L. Williams, E. M. Becher, S. B. Shrestha, Z. Nasir, B. J. Lofink, V. H. Santos, H. Patel, X. Peng, L. Sun, Advanced Composites and Hybrid Materials, 2018, 1, 177-184, doi: 10.1007/s42114-017-0006-1.

[27] D. Zhang, B. L. Williams, V. H. Santos, B. J. Lofink, E. M. Becher, A. Partyka, X. Peng, L. Sun, Engineered Science, 2020, 12, 106-112, doi: 10.30919/es8d1134.

[28] B. L. Williams, H. Ding, Z. Hou, P. O. Paul, F. A. Lewis, A. T. Smith, L. Sun, Advanced Composites and Hybrid Materials, 2021, 4, 662-669, doi: 10.1007/s42114-021-00299-w.

[29] A. T. Smith, A. M. LaChance, S. Zeng, B. Liu, L. Sun, Nano Materials Science, 2019, 1, 31-47, doi: 10.1016/j.nanoms.2019.02.004.

[30] J. Yu, J. Liu, A. Clearfield, J. E. Sims, M. T. Speiegle, S. L. Suib, L. Sun, Inorganic Chemistry, 2016, 55, 12036-12041, doi: 10.1021/acs.inorgchem.6b02203.
[31] R. Gottesman, S. Shukla, N. Perkas, L. A. Solovyov, Y. Nitzan, A. Gedanken, Langmuir, 2011, 27, 720-726, doi: 10.1021/la103401z.

[32] L. Sun, W. J. Boo, A. Clearfield, H. J. Sue, H. Q. Pham, Journal of Membrane Science, 2008, 318, 129-136, doi: 10.1016/j.memsci.2008.02.041.

[33] S. Nam, M. W. Easson, B. D. Condon, M. B. Hillyer, L. Sun, Z. Xia, R. Nagarajan, RSC Advances, 2019, 9, 10914-10926, doi: $10.1039 / \mathrm{c} 9 \mathrm{ra} 00763 \mathrm{f}$.

\section{Author information}

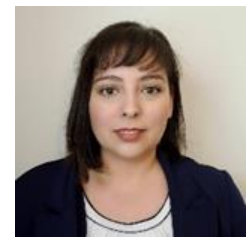

Sonia E. Chavez received her Ph.D. from the University of Connecticut in Polymer Science in 2020. Her research interest is associated with barrier coating for food packaging.

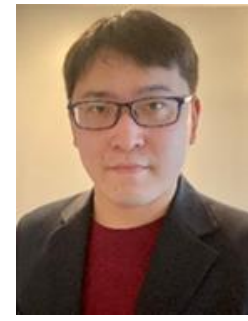

Hao Ding is a Ph.D. candidate in Chemical Engineering at the University of Connecticut. He received his B.S. degree in Macromolecular Materials and Engineering from Fudan University, China, in 2016. Currently, He works in Dr. Luyi Sun's group on functional hydrogels and organic/inorganic nanocomposites.

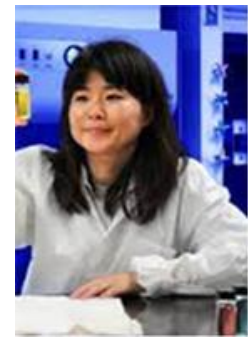

Sunghyun Nam is a material engineer in the US Department of Agriculture in New Orleans, Louisiana. She graduated from the Georgia Institute of Technology with a Ph.D. in Polymer, Textile, and Fiber Engineering. Her research interests include cellulose, nanoparticles, antimicrobials, flame retardants, and green processes.

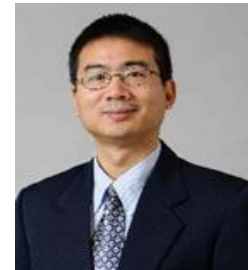

Luyi Sun received his Ph.D. from the University of Alabama in 2004. After his postdoctoral training at Texas $A \& M$ University, he worked at TOTAL Petrochemicals USA, Inc. from 2006 to 2009. He was an assistant professor at Texas State University from 2009 to 2013. Dr. Sun joined the University of Connecticut as an associate professor in 2013 and was promoted to professor in 2018. His research focuses on the design and synthesis of nanostructured materials for various applications

Publisher's Note: Engineered Science Publisher remains neutral with regard to jurisdictional claims in published maps and institutional affiliations. 